\title{
Directing urban development to the right places: Assessing the impact of urban development in an estuarine environment
}

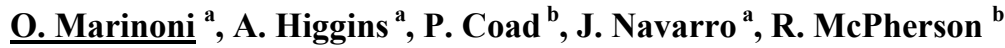 \\ ${ }^{a}$ CSIRO Ecosystem Sciences, Dutton Park, Queensland, Australia \\ ${ }^{b}$ Hornsby Shire Council, Hornsby, New South Wales, Australia \\ Email: oswald.marinoni@csiro.au
}

\begin{abstract}
The New South Wales Government regularly imposes dwelling increases on local councils across the State. These increases are predicated on the supposition that the population of the Greater Sydney Metropolitan Area will continue to expand exponentially, and that accommodation for this burgeoning population needs to be found. Given this continued pressure from State Government, Councils in the affected regions need to understand the carrying capacity for land within their local government areas. The methods by which the State Government and Councils currently decide where people are to be housed are based on limited information with little scientific understanding of the consequences of these actions on the local environment. The challenge for Councils is to ensure an adequate supply of houses to meet State Government requirements, while ensuring that development is socially, environmentally and economically sustainable. The work presented in this paper describes the development of a method to determine the impact of development on a receiving waterway based on water quality criteria. It is based on mathematical programming linked with multi-criteria analysis and kinematic wave equation representing travel time of pollutants to the estuary. A GIS component is applied to underpin multiple spatial constraints on where housing development can take place, and to provide an effective means of visually analysing land development scenario impacts produced by the model. A test case study that demonstrates the developed method is presented. As impacts on waterway health are a concern with regards to virtually any urban development we see a wide application of the proposed methodology well beyond the study area.
\end{abstract}

Keywords: Urban development, Estuary, Multi-Criteria Analysis, Impact metric, Optimisation 


\section{INTRODUCTION}

The New South Wales Government's Metropolitan Strategy (NSW Department of Planning 2005) is a strategic document that provides the strategic direction to manage growth and development over the next 25 years. According to this strategy, Sydney's population is anticipated to grow by 1.1 million people between 2004 and 2031, from a current population of 4.2 million to 5.3 million. With average household sizes anticipated to fall from 2.65 to 2.36 persons per private dwelling by 2031, the NSW Government predicts that 640,000 new homes will be required in Sydney to cater for the growth in the population with the Hornsby Council asked to meet a target of 11,000 dwellings. Central to the study presented is the recognition that future development scenarios imply potential risks to waterways - in this particular case to the Lower Hawkesbury Estuary. These risks are related to increases in impervious areas thus changing hydrological regimes with potentially higher erosive capacity as well as increased nutrient input into the estuary.

\section{PHYSICAL SETTING}

The Lower Hawkesbury River Estuary is a drowned river valley, which was incised into Hawkesbury sandstone bedrock during the historical ice ages when sea levels were much lower than present (Haines, Fletcher et al. 2008). It is located north of Sydney, New South Wales, Australia (Figure 1). Hydrologically, the Lower Hawkesbury River sits in the greater Hawkesbury-Nepean River catchment which has a total area of approximately $22,000 \mathrm{~km}^{2}$. The river valley has a unique morphology including tall, highly weathered sandstone cliffs and gorges, open waterways, secluded bays and an expanse of natural vegetation making it one of the most visually spectacular waterways in New

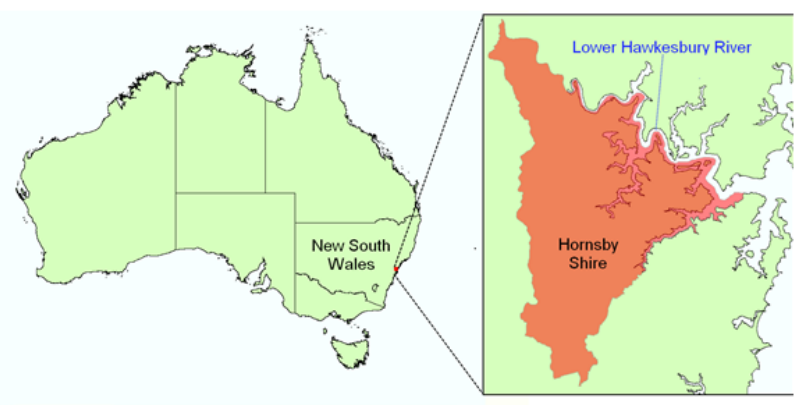

Figure 1: Location of the study area.

South Wales. The Lower Hawkesbury supports the 2nd largest estuary fishery and the 2nd largest oyster farming industry in NSW (Haines, Fletcher et al. 2008). It is also a very popular destination for a large number of recreational visitors predominantly from the Sydney metropolitan area.

\section{ESTUARINE ASSETS}

Future development scenarios imply potential risks to the Lower Hawkesbury Estuary. These risks are related to increases in impervious areas thus changing hydrological regimes with potentially higher erosive capacity as well as increased nutrient input into the estuary. In the Lower Hawkesbury Estuary Management Plan (Haines et al., 2008) a whole range of estuarine assets have been defined and future management activities should focus on the protection of assets in order to achieve long-term goals. To assess the potential impacts of new development onto the assets an approach was developed which captures the impact of development in a performance score. However, it was not possible to capture all listed estuarine assets as some assets had a considerable overlap spatially and functionally (e.g. functional and sustainable ecosystems, water quality), were difficult if not impossible to measure (e.g. community character, effective governance) or were captured as a spatial constraint (e.g. scenic amenity, see next section). Ultimately, 5 estuarine assets were considered: waterbody, areas of primary contact, areas of secondary contact, oyster farms and macrophytes.

\section{METHODS}

\subsection{Spatial constraints}

New urban development will not be arbitrarily placed across the landscape. To map the areas where urban development can take place, spatial constraints were defined and visualised as various digital layers in a GIS. The overlay of these layers mapped the go and no-go zones for new development. Most spatial constraints were adopted from the Hornsby Shire Housing Strategy (Hornsby Shire 2010). The processing of the data was done on a raster cell basis;

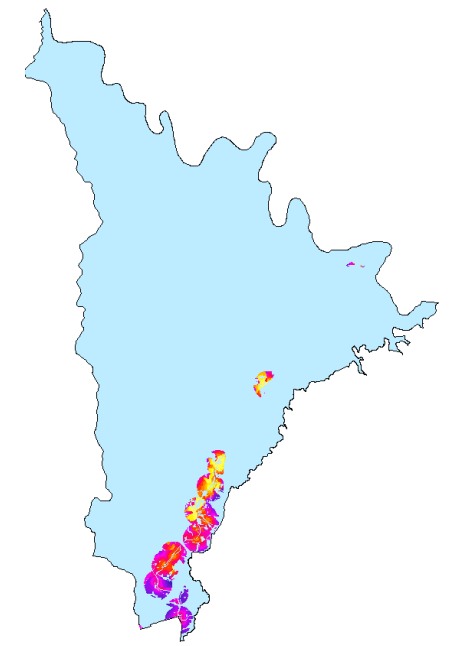

Figure 2: Remaining go zones for development. 
whereby existing vector data were converted to raster data with a spatial resolution of $50 \mathrm{~m}$. Spatial constraints included (i) proximity to infrastructure which includes railroad stations and business centres (1 $\mathrm{km}$ buffer was used), (ii) proximity to sewer infrastructure, (iii) a $50 \mathrm{~m}$ no-go zone around creeks, (iv) no development in existing parks, sport grounds, transport corridors and (v) excluding development from areas that are highly prone to bushfire or (vi) have a high scenic amenity. Figure 2 shows the zones within the shire area that fulfilled all spatial constraints (go zones for development). These zones represent the pixels across which the developed optimisation model will distribute new dwellings.

\subsection{Adding of new dwellings}

The different housing stock densities considered were (i) detached housing with a yield of 15 dwellings per hectare (low density); (ii) semidetached or townhouse dwellings with a yield of 55 dwellings per hectare (medium density) and (iii) multi-storey apartments with an estimated yield of 80 dwellings per hectare (high density). Since the spatial resolution in the model is $50 \mathrm{mx} 50 \mathrm{~m}$, the numbers per hectare are divided by 4 . There are rules as to how new dwellings are added to each pixel. In existing urban areas, we assumed low density housing pixels are replaced with townhouses or multi-story apartments. Existing medium density area pixels will be converted to high density. In open space areas, detached dwellings are added to pixels rather than townhouses or apartments. No dwellings are added to forest areas. The proportion of apartments to townhouses to detached dwellings was 20:4:1 which reflects a bias towards a minimization of the use of available land. These proportions can however be changed in the model.

\subsection{Pollutant concentrations and travel time}

As overland flow travels down towards the estuary, it may flow through many different zones of land use. Each land use will have different characteristics with regards to the time it takes to travel across as well as the average amount of pollutants that will mobilised and transported by the water. Standard Event Mean Concentrations (EMC) were applied for different land uses and pollutants. For this study the shaded values in Table 1 have been used.

Table 1: Typical EMC values used in New South Wales (NSW Department of Environment Climate Change and Water 2010).

\begin{tabular}{|c|c|c|c|c|c|c|c|c|c|}
\hline \multirow[b]{2}{*}{ LAND USE } & \multicolumn{3}{|c|}{$\mathrm{EMC}(\mathrm{mg} / \mathrm{L})$ for $\mathrm{TSS}$} & \multicolumn{3}{|c|}{$\mathrm{EMC}(\mathrm{mg} / \mathrm{L})$ for $\mathrm{TP}$} & \multicolumn{3}{|c|}{$\mathrm{EMC}(\mathrm{mg} / \mathrm{L})$ for $\mathrm{TN}$} \\
\hline & LOW & TYPICAL & HIGH & LOW & TYPICAL & $\mathrm{HIGH}$ & LOW & TYPICAL & $\mathrm{HIGH}$ \\
\hline residential & 40.00 & 140.00 & 500.00 & 0.08 & 0.25 & 0.80 & 0.70 & 2.00 & 6.00 \\
\hline industrial & 40.00 & 140.00 & 500.00 & 0.08 & 0.25 & 0.80 & 0.70 & 2.00 & 6.00 \\
\hline commercial & 40.00 & 140.00 & 500.00 & 0.08 & 0.25 & 0.80 & 0.70 & 2.00 & 6.00 \\
\hline rural & 20.00 & 90.00 & 400.00 & 0.08 & 0.22 & 0.60 & 0.70 & 2.00 & 5.00 \\
\hline forest/natural & 10.00 & 40.00 & 150.00 & 0.03 & 0.08 & 0.20 & 0.40 & 0.90 & 2.00 \\
\hline
\end{tabular}

We computed the travel time (see section 5) of the overland flow which is the time taken for rainwater to travel from its point of contact with the land to a river or stream. It is a function of slope and surface roughness. Travel time can be used as a proxy for water quality. A higher travel time generally implies improved water quality as longer contact with the landscape ensures a greater absorption of pollutants. Roughness coefficients have been taken from Higgins et al. (2008). As pollutant concentrations will change with travel time, the travel time was later linked to pollutant concentrations that are being transported across the landscape. This interrelation is described in section 5.

\subsection{Impact on estuarine assets}

The mapped locations of the estuarine assets were converted into raster datasets. The major tributaries flowing towards the estuary where divided into segments. This division was done visually. In a next step the asset raster datasets were "intersected" with the subcatchment creek segments (each subcatchment has a unique ID) and the asset pixels within individual segments are counted. This allows building a matrix (Table 2). To avoid a bias regarding the spatial extent of an asset it was decided to convert the raw matrix into a binary matrix (Table 4). The information provided in the binary asset matrix is later combined with the modelled pollutant peak flow discharges that are computed per subcatchment. The higher the pollutant inflow from a subcatchment into the estuary and the more assets are present, the higher the cumulative impact on to the estuarine assets. As asset information is provided per subcatchment it is possible to determine partial impact scores. 

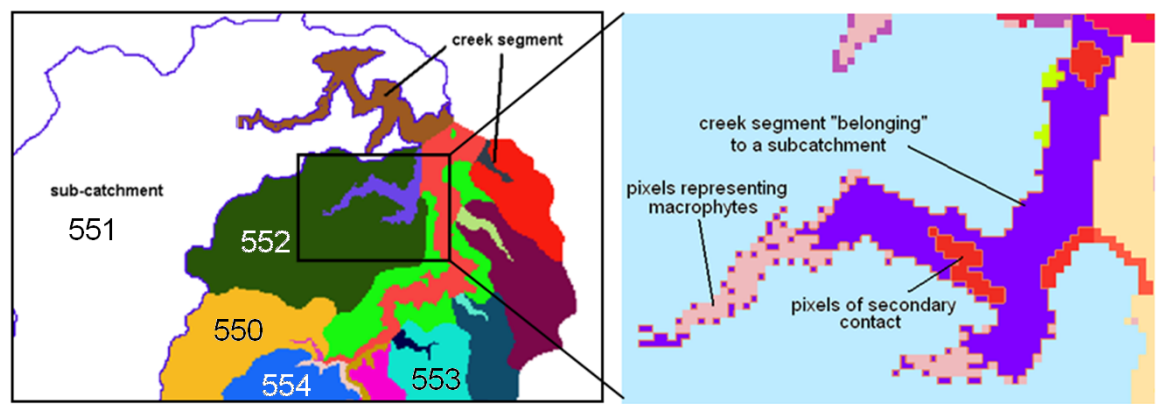

Figure 3: Division of a major catchment into subcatchments and principle of the definition of creek segments belonging to individual subcatchments (numbers represent unique subcatchment IDs).

Table 2: Excerpt of a non binary asset matrix showing the number of asset pixels within subcatchments.

\begin{tabular}{|c|c|c|c|c|c|}
\hline $\begin{array}{c}\text { Subcatchment } \\
\text { code }\end{array}$ & $\begin{array}{c}\text { Pixels } \\
\text { waterbody }\end{array}$ & $\begin{array}{c}\text { Pixel primary } \\
\text { contact }\end{array}$ & $\begin{array}{c}\text { Pixel secondary } \\
\text { contact }\end{array}$ & $\begin{array}{c}\text { Pixel oyster } \\
\text { farms }\end{array}$ & $\begin{array}{c}\text { Pixels } \\
\text { macrophytes }\end{array}$ \\
\hline$\ldots$ & & & & & \\
\hline 551 & 752 & 69 & 0 & 0 & 12 \\
\hline 552 & 276 & 48 & 58 & 0 & 29 \\
\hline 553 & 99 & 0 & 0 & 0 & 15 \\
\hline$\ldots$ & & & & & \\
\hline
\end{tabular}

\section{OPTIMISATION AND MODEL FORMULATION}

The model is formulated as a non-linear integer programming problem with parameters capturing the location, the type of dwelling present at a location $i, j$, the type of dwelling being added, the current land use as well as the subcatchment a pixel at location $i, j$ belongs to. It also takes into account permissible cells for constructing new dwellings as defined through the spatial constraints. The number of new dwellings constructed must equal the number specified.

\section{Runoff into the Estuary}

A proxy of the concentration of run-off into the estuary is the Kinematic Wave equation of travel time from each point on the landscape to the estuary. There are several versions of the formula that could be used (see Wong (2009) for a survey). We used the common version by Woolhise and Ligget (1967) which was later used by Higgins et al. (2008) for optimisation of conservation reserves. The calculation of travel time is based on a travel path (e.g. to a river), which is calculated using a DEM. It is also based on the roughness of the landscape captured by Manning's roughness coefficient. Using the Kinematic Wave equation, the travel time through cell located at $i \in I, j \in J$ is

$$
\frac{D_{i j} n_{i j}{ }^{0.6}}{r_{i j}{ }^{0.4} s_{i j}{ }^{0.3}}
$$

where:

$n_{i j}=$ Manning's roughness coefficient for the cell $i \in I, j \in J$ based on the given land use in cell $i j$

$s_{i j}=$ decimal slope of the cell at $i \in I, j \in J$ as generated from the digital elevation map

$D_{i j}=$ distance travelled through the cell at $i \in I, j \in J$ based on grid cell size

$r_{i j}$, $=$ rainfall excess rate (inch/hour) at the cell located at $i \in I, j \in J$

The travel time (overland component) of water from the cell at $i \in I, j \in J$ to the waterway (river or stream) is

$$
T_{i j}=\sum_{l \in I} \sum_{\substack{m \in J \\ l, m \in R_{i j}}} \frac{D_{l m} \cdot\left(\left(1-x_{l m}\right) \cdot n_{l m}+x_{l m} \cdot \hat{n}_{l m}\right)^{0.6}}{r_{i j}^{0.4} \cdot s_{l m}^{0.3}}
$$

where:

$\hat{n}_{l, m}=$ Manning's roughness coefficient for the cell located at $i \in I, j \in J$.

$R_{i, j}=$ travel path of sequence of cells from cell located at $i \in I, j \in J$ to catchment outlet. This takes into account the path of flow through intermediate sub-catchments leading to the estuary.

The objective of the model is to maximise total cumulative travel time from all overland cells in the catchment to the estuary

$\operatorname{Max} \mathrm{Z}=\sum_{i \in I} \sum_{j \in J} T_{i j}$ 


\section{Extension to Calculating Peak Discharge of EMC's}

While the model maximises cumulative travel time, we calculate the peak unit discharge as a function of travel time, so that impact of EMC into the estuary can be estimated. The peak unit discharge (U.S. Soil Conservation Service 1986) of run-off from cell $i, j$ to the estuary, given a mm of rain, is:

$q_{i, j}=10^{C_{0}+C_{1} \log _{10} T_{i, j}+C_{2}\left(\log _{10} T_{i, j}\right)^{2}}$

where coefficients $C_{0}, C_{1}$ and $C_{2}$ depend on the land use in the grid cell (U.S. Soil Conservation Service 1986). The peak flow ( $\mathrm{m}^{3}$ per second) of EMC's into the estuary per mm of rain is

$\sum_{i} \sum_{j} A \cdot q_{i j} \cdot E_{i, j}$

where

$\mathrm{A}=$ area of grid cell, accommodating translation between units (volume and distance),

$E_{i, j}=$ EMC discharge (mg/litre) per litre of water leaving grid cell $i, j$, accommodating its land use.

The model starts distributing dwellings within the pixels of the go-zones (Figure 2). Total travel time (= the sum of the travel times from each pixel) is then computed for each sub-catchment and summed across the subcatchments. The model iterates (= re-distributes dwellings) until it converges to a solution with a maximized total travel time. Peak flow discharges are computed for this solution (Figure 4) and put in relation to two reference scenarios. Reference scenario 1 is the current development which is to provide an idea about the order of magnitude of change caused by new development compared to the present situation. Reference scenario 2 captures a pre-European situation, assuming an entirely forested Shire area which is to give an idea regarding the deviation of development from an "ideal" situation.

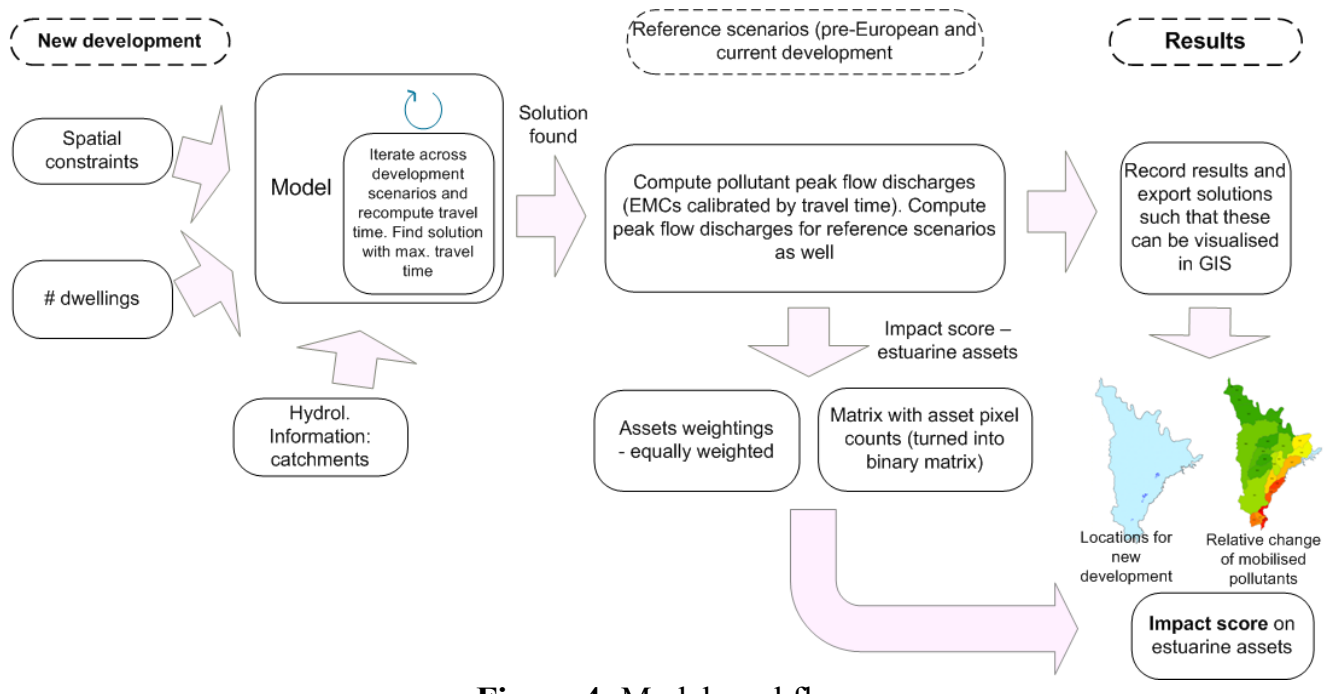

Figure 4: Model workflow

\section{CASE STUDY}

A test evaluation was performed for a scenario where 5000 new dwellings were added. The results presented are of no policy relevance. It is assumed that each pixel gets the same amount of rainfall. Simulated values for rainfall can however be easily integrated. The resulting travel times and accumulated EMC values are used to compute the peak flow discharges of pollutants (equation 6) which are then used to compute an average load $l$ from the peak flow discharges $c$ of the three pollutants TN, TP and TSS with

$$
l=\sum_{i=1}^{\mathrm{k}} \frac{1}{\mathrm{k}} \mathrm{c}_{\mathrm{i}} \quad \text { with } k=\text { number of pollutants (here } k=3 \text { ) }
$$

This is based on the assumption that each pollutant has a similar impact on water quality. The values for $l$ are then used to compute the impact on the estuarine assets and the relative change of mobilised pollutants within subcatchments. Figure 5 shows the development solution suggested by the model. Table 3 gives an overview of the pollutant concentrations that are mobilised by new development, current development as well as under 
historic conditions (pre-European settlement). Due to space limitations only values for 3 of the 20 subcatchments are presented here.

Table 3: Pollutant peak flow discharges for the three scenarios (all values in $\mathrm{kg} / \mathrm{sec} \mathrm{x} \mathrm{mm}$ ).

\begin{tabular}{|c|c|c|c|c|c|c|c|c|c|}
\hline & \multicolumn{3}{|c|}{ TN } & \multicolumn{3}{c|}{ TP } & \multicolumn{3}{c|}{ TSS } \\
\hline $\begin{array}{c}\text { \# sub- } \\
\text { catchment }\end{array}$ & New & Current & $\begin{array}{c}\text { Pre } \\
\text { European }\end{array}$ & New & Current & $\begin{array}{c}\text { Pre } \\
\text { European }\end{array}$ & New & Current & $\begin{array}{c}\text { Pre } \\
\text { European }\end{array}$ \\
\hline$\ldots$ & & & & & & & & & \\
\hline 551 & 0.00310 & 0.00308 & 0.00151 & 0.00039 & 0.00039 & 0.00019 & 0.21710 & 0.21564 & 0.10556 \\
\hline 552 & 0.00077 & 0.00077 & 0.00060 & 0.00010 & 0.00010 & 0.00007 & 0.05376 & 0.05376 & 0.04178 \\
\hline 553 & 0.00065 & 0.00065 & 0.00023 & 0.00008 & 0.00008 & 0.00003 & 0.04533 & 0.04531 & 0.01596 \\
\hline$\ldots$ & & & & & & & & & \\
\hline
\end{tabular}

For each scenario the average load $l$ is computed and relative changes for $l$ are computed. These changes can be linked to a spatial layer of the subcatchments (Figure 6). It becomes apparent which subcatchments face the biggest changes regarding a mobilisation of pollutants. This informs planners and water quality managers where and to which degree changes regarding pollutants can be expected relative to the current situation. Though not presented here, the model also provides values for an entirely forested Shire area (pre-European) which allows for the assessment of the impact as compared to an ideal (undeveloped) situation.

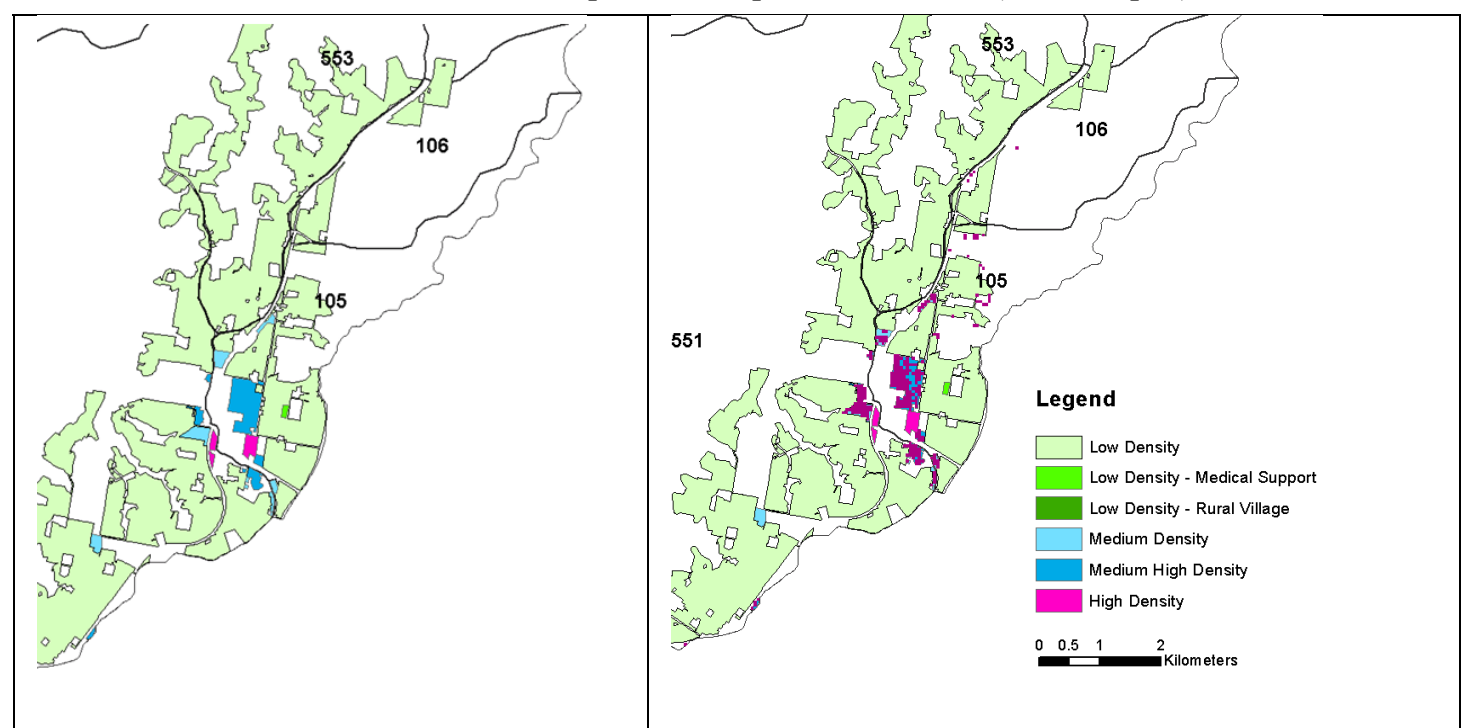

Figure 5: Suggested locations for 5000 new dwellings. Left: Existing urban development Right:

Existing urban development plus pixels that show the suggested locations for new development. It can be seen that the medium and medium-high density areas are targeted

\section{Impact on estuarine assets}

The binary asset matrix (Table 4) was developed from the asset matrix (Table 2).

Table 4: Binary asset matrix (excerpt, 20 subcatchments in total).

\begin{tabular}{|c|c|c|c|c|c|}
\hline $\begin{array}{c}\text { Subcatch. } \\
\text { code }\end{array}$ & $\begin{array}{c}\text { Pixels } \\
\text { waterbody }\end{array}$ & $\begin{array}{c}\text { Pixel primary } \\
\text { contact }\end{array}$ & $\begin{array}{c}\text { Pixel secondary } \\
\text { contact }\end{array}$ & $\begin{array}{c}\text { Pixel oyster } \\
\text { farms }\end{array}$ & $\begin{array}{c}\text { Pixels } \\
\text { macrophytes }\end{array}$ \\
\hline$\ldots$ & & & & & \\
\hline 551 & 1 & 1 & 0 & 0 & 1 \\
\hline 552 & 1 & 1 & 1 & 0 & 1 \\
\hline 553 & 1 & 0 & 0 & 0 & 1 \\
\hline$\ldots$ & & & & & \\
\hline
\end{tabular}

As all 5 assets were considered equally important by Council each asset receives a weight of 20.0\% $=0.2$. The binary asset matrix is then multiplied with the respective weights and the weighted peak flow discharge $l$ (e.g. for \#551: $l=0.333 \times(0.00310+0.00039+0.21710)=0.073$; new development, values from Table 3). Subcatchment \#551 has a partial impact score of $0.073 \times(0.2+0.2+0+0+0.2)=0.04$. If this computation is performed across all 20 subcatchments the sum of the partial impact scores is 0.303 . This value is more meaningful if it is compared to impact values of the reference scenarios. In the case study the impact scores are 0.302 (rounded) for the current development and 0.166 for pre-European conditions. The absolute difference between the impact scores of the current and new development scenario is in fact 0.000783 which 
is equal to a relative change of $0.26 \%$. The additional impact on estuarine assets caused by new development is hence marginal. The change to pre-European conditions is more significant. The absolute change is 0.136 $(=0.303-0.166)$ which corresponds to a relative change of $82.26 \%$.
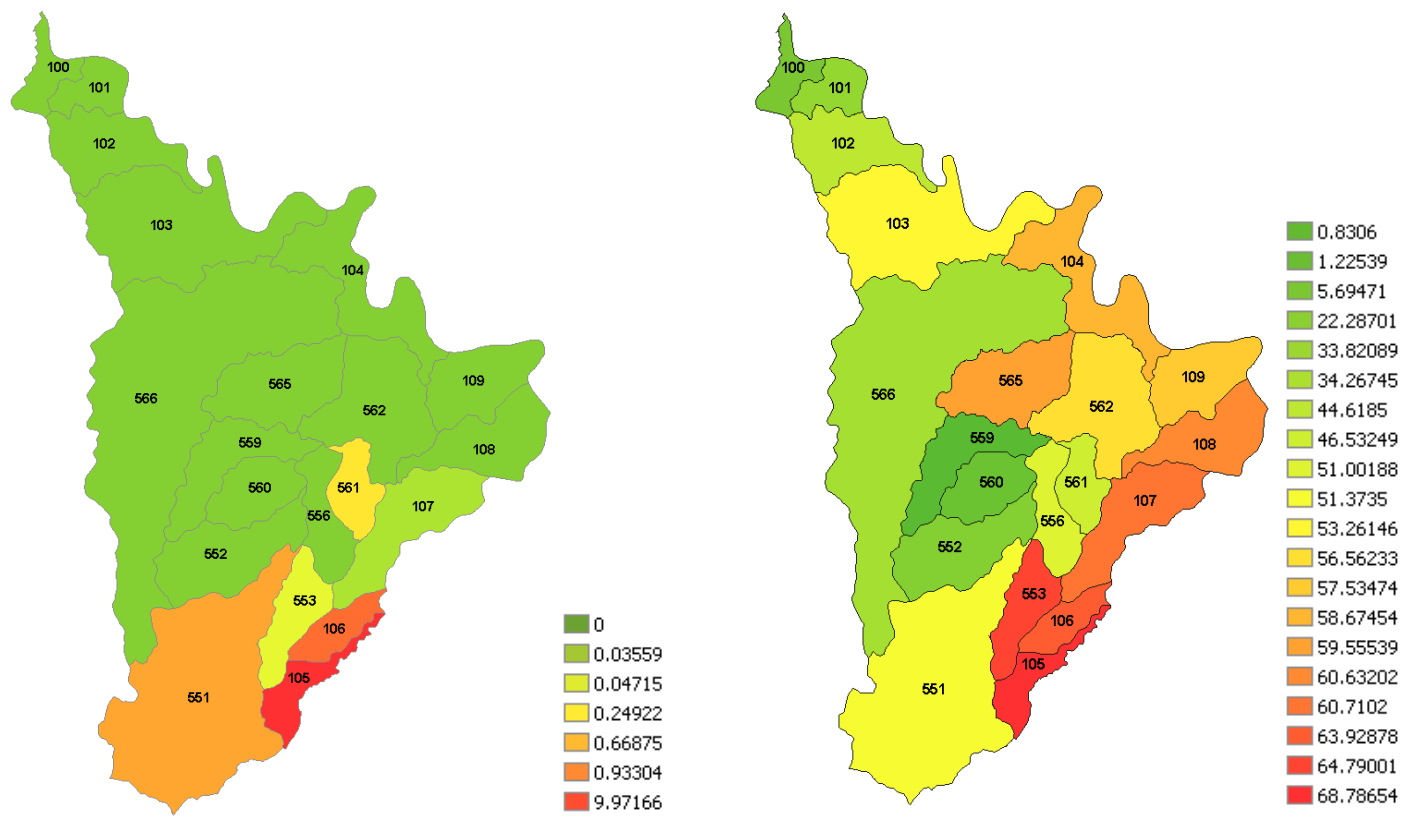

Figure 6: Relative changes [\%] of average pollutant loads. Left: relative change new-current development. Right: new development-historic situation (note new development $=$ current development plus additional new dwellings). Values to compute relative changes were taken from Table 3.

\section{DISCUSSION AND CONCLUSIONS}

This paper has presented a new model which will help informing the planning of urban development but will also facilitate estuarine management. The model is flexible in that it accommodates for a variety of spatial constraints. Besides proximity or binary spatial constraints, development can also be targeted to individual suburbs, along road corridors, or to any zone explicitly mapped by planners. We also presented a multicriteria analysis (MCA) approach to determine the impact of urban development on estuarine assets using reference scenarios as benchmarks. The model can easily be transferred across to other areas and applied to other estuaries or waterways.

\section{ACKNOWLEDGMENTS}

The authors would like to thank Hornsby Shire Council and the CSIRO Climate Adaptation Flagship for the funding of this research.

\section{REFERENCES}

Haines, P., M. Fletcher, et al. (2008). Lower Hawkesbury Estuary Management Plan: 330p

Higgins, A. J., S. Hajkowicz, et al. (2008). "A multi-objective model for environmental investment decision making." Computers \& Operations Research 35(1): 253-266

Hornsby Shire (2010). Hornsby Sire Housing Strategy. Hornsby. 1: 11

NSW Department of Planning (2005). City of Cities: A Plan for Sydney's Future. N. G. D. o. Planning. Sydney

NSW Department of Environment Climate Change and Water (2010). Proposed typical values for EMC used statewide, personal communication.

U.S. Soil Conservation Service (1986). Technical Release 55: Urban Hydrology for Small Watersheds. U. U. S. D. o. Agriculture)

Wong, T. S. W. (2009). "Evolution of Kinematic Wave Time of Concentration Formulas for Overland Flow." Journal of Hydrologic Engineering 14(7): 739-744.

Woolhise Da and J. A. Liggett (1967). "Unsteady 1-dimensional flow over a plane - rising hydrograph." Water Resources Research 3(3): 753-771. 